\title{
Two decades of haemophilia treatment in the Netherlands,
} 1972-92

\author{
A H M TRIEMSTRA, C SMIT, H M VAN DER PLOEG, E. BRIET and F. R ROSENDAAL \\ Department of Medical Psychology, Vrije Universitett Amsterdam, Netherlands Hemophilta Society, Badhoevedorp, \\ Department of Clinical Epidemiology, University Hospital Leiden, Hemostasts and Thrombosis Research Centre, University \\ Hospital Letden, the Netherlands
}

Summary. Four questionnaire surveys were conducted over a period of 20 years to evaluate long-term effects of haemophilia treatment in the Netherlands. The response to the prestructured questionnaires in 1972, 1978, 1985 and 1992 varied between $70 \%$ and $84 \%$. Data concerned treatment modalities, bleeding epısodes, hospitalization, absenteeism, joint impairment and employment. Results over the period 1972-92 for patients with severe and moderately severe haemophilia showed that the use of prophylaxis had sharply increased (from $21 \%$ to $45 \%$ ), as was the case for home treatment (from $4 \%$ to $62 \%$ ) Consequently, the annual mean number of bleeds diminished from 19 to 13 . Absence from school was markedly reduced (from 32 to 5 days), and sick leave in employed patıents had also dimınıshed (from 26 to 22 days). Furthermore, the use of inpatient hospital facilities, as well as employment in haemophilia patients, had nearly equalled that of the general Dutch male population. The self-reported degree of joint impairment showed no overall improvement, but in patients aged under 35 years there seemed to be a slight reduction in severe impairment. Patıents aged under 15 years finally had no severe impairment at all. Social participation can only be further improved if arthropathy is prevented from an early age. Therefore adequate prophylactic regimens and close monitoring of joint impairment in young adults are needed.

Keywords haemophilia, prophylaxis, home treatment, hospitalızation, absenteeism, joint impairment.
At the end of the 1960s, clotting factor products became avallable for substitution therapy in haemophilia and a new era in haemophilia care began. Since then the physical, psychological and social condition of haemophilia patients has gradually improved [1-5]. In patients with a high frequency of bleeds, 1.e. with severe or moderately severe haemophilia, there has been a shift from on-demand treatment to more prophylactic therapy. Prophylaxus from an early age was expected to be effectuve in reducing the morbidity of haemophilia, especially in terms of preventing haemarthroses and haemophilic arthropathy $[1,6,7]$. Home treatment was introduced in the early 1970 s to optimalize the treatment in patients with a high bleeding tendency. The situation in which patients themselves administer factor concentrates at home or with the help of others, allows for the early treatment of bleeding episodes before the appearance of physical signs [8]. Consequently, arthropathy can be prevented, and this might subsequently lead to a reduction

Recelved 5 December 1994, accepted 12 January 1995 of absenteeism from school or work and a diminished reliance on hospital facilities [8-10].

To evaluate the long-term effects of modern haemophilia treatment on a large scale, we conducted four national questionnaire surveys among haemophilia patients. This article reports on the results collected over a period of two decades (1972-92). By comparing crosssectional data on the number of bleeding episodes, hospitalization, absenteeism, joint impairment, and social participation, we describe the extent to which a change in treatment modalities contributed to an improvement in the medical and social circumstances of haemophiliacs. Comparisons with national statistics on absenteeism, hospitalization, and social participation will show whether further improvements can be established.

\section{Methods}

Pattents and procedures. Four nationwide postal surveys were conducted in 1972, 1978, 1985 and 1992. The study population consisted of haemophilia patients who were listed with the Netherlands Hemophilia Society, with the 
haemophilıa treatment centres, or on updated mailing lists from our previous survey(s). An extensive search for addresses enabled us to send questionnaires to 639, 1051, 1162 and 1263 patients, respectively. The response was calculated for all questionnaires returned, irrespective of diagnosıs (1.e. haemophilia or other bleeding disorders) and whether the recerved forms were fully completed. Only participants diagnosed with haemophilia A or B were included in the final analyses. The severity of haemophilia was classified according to the residual percentage of factor VIII or IX clotting activity. severe $(<1 \%)$, moderate $(1-5 \%)$, or mild $(>5 \%)$. The selfreported type and severity of haemophilia was verified with data obtained from the treatment centres.

All four prestructured questionnaires covered the following issues the current treatment modality and regimen, the presence of inhibitors, the annual number of bleeding episodes, the use of inpatient hospital care, absence from school or work, degree of joint impairment, employment, and disability. The questionnaires also included new issues raised in haemophilic care, e.g. home treatment (in 1978) and HIV infections (1985 and 1992).

Data analyses. Analyses were conducted according to the severity of haemophilia. Data on the treatment modality, the number of bleeding episodes, the use of hospital facilities, and absence from school or work referred to the year that preceded the questionnaire surveys. The use of prophylaxis refers to a group of patients who predomınantly received prophylaxis, from which we excluded patients who predominantly received treatment on demand and short-term prophylaxıs at various tımes.

The prevalence of haemophilia in 1992 was estumated from data of 980 respondents and 240 non-respondents of whom the date of birth and the severity classification were known. The age-specific prevalence was calculated as the number of listed haemophilıa patients per 100,000 Dutch males in each age category.

Self-reported measures on joint impairment were obtained for a series of joints, with possible scores of 0 (no impairment), 1 (some impairment without daily problems), 2 (some impairment with daily problems), and a maximum of 3 (severe impairment with complete loss of function). Because shoulder foints and the hips are seldomly affected $[1,11]$ and patients with the moderate form of haemophilia rarely develop chronic arthropathy [12], scores for ankles, knees and elbows in patients with severe haemophilia were used in assessing the degree of joint impairment. As joint impairment progresses with age and older patients are more likely to have joint damage because of a lack of treatment in the past, the results presented are stratified for age.

The employment status was defined for respondents aged 15-64 years who were either 'active' (1.e. employed, with a paid job) or 'inactive' (administratively registered as unemployed or disabled under the existing Dutch social security laws). To describe social participation in haemophiliacs, an 'inactivity ratıo' was calculated by dividing the proportion of 'inactive' patients with severe or moderately severe haemophilia by the proportion of 'inactive' Dutch males [2]. Thus, the percentage of inactive haemophiliacs will be relative to the percentage of inactives in the general male population, and ratios exceeding a value of 1 represent a reduced social participation of haemophilia patients. Descriptive statistics for age, the use of hospital facilities, absence from work, and employment were compared to national figures for the general male population that were provided by Statıstics Netherlands.

\section{Results}

\section{Response and participants}

The response to the questionnaires was $84 \%(n=540)$ in $1972,70 \%(n=736)$ in $1978,81 \%(n=941)$ in 1985 and $78 \%(n=983)$ in 1992. Respondents who were excluded from analyses concerned patients of whom the type of haemophilia remained unknown (1972: $n=48$; 1978: $n=131$ ), those who were carriers or patients affected with other clotting factor deficiencies (1972: $n=44$; 1978: $n=16$; 1985. $n=2$; 1992: $n=29$ ), and respondents who returned uncompleted questionnaires with little or no data (1972. $n=1 ; 1978: n=29 ; 1985: n=6 ; 1992: n=3)$. A total of $447,560,933$ and 980 partıcipants, meeting the inclusion criteria of having haemophilia $A$ or $B$, remained for analyses.

Seventy-five percent $(n=738)$ of the patients in 1992 participated in an earlier survey, including 232 patients who responded to all preceding surveys. The mean age of participants increased from 21 years in 1972 to 32 years in 1992, but remained lower than the mean age of Dutch males which had increased from 32 to 36 years over the same period. The distribution of $87 \% \quad(n=853)$ with haemophilia $\mathrm{A}$ and $13 \%(n=127)$ with haemophilia $\mathrm{B}$ in 1992 was sımılar in all four surveys. Of all participants in $1992,39 \%$ had severe haemophilia $(n=387), 18 \%$ had moderately severe $(n=173)$ and $43 \%$ had mild haemophilia $(n=420)$.

\section{Prevalence}

The age-specific prevalence of haemophilia in 1992 is shown in Fig. 1, with separate distributions for the severely and non-severely affected patients. The overall prevalence found in 1992 was 16.3 per 100,000 males. The maximum prevalence of 20.2 per 100,000 males in the age 


\section{Prevalence (per 100,000 males)}

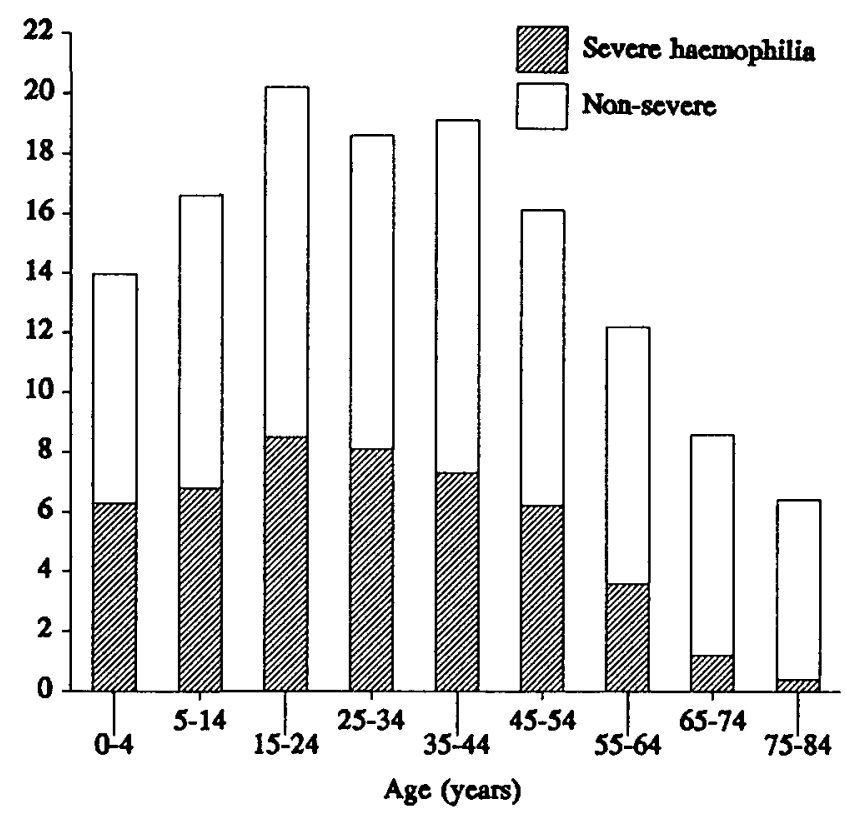

Fig. 1. Prevalence of haemophilia in the Netherlands in 1992 per 100,000 males, with separate distributions for severe and non-severe haemophilia

group of 15-24 years estımates the prevalence at birth, whereas lower values in the younger and older age categories are likely to be the result of delayed diagnoses and excess mortality in the past, respectively.

\section{Treatment outcomes in severe and moderately severe haemophilia}

Table 1 presents an overview of results on treatment modalities, frequency of bleeds, hospital admissions, and absence from school or work for patients with severe or moderately severe haemophilia. Prophylactic treatment was prescribed to $21 \%(n=52)$ of these patients in 1972 , which increased to $45 \%(n=251)$ in 1992 . The application of home treatment in these patients showed an even larger increase from $4 \%(n=9)$ in 1972 to $62 \% \quad(n=349)$ administering clottıng factor products at home in 1992. The mean number of manifest bleeds per year in patients with severe or moderately severe haemophilia declined from 19 in 1972 to 13 in 1992. The decrease was most prominent in the severely affected patients, who reported 25 bleeds per year in 1972 and 16 in 1992. The most frequent sites of haemorrhages in 1992 were joints $(77 \%)$, and only three of the 13 bleeds on average were located in muscles or soft tissues.

The total number of days spent in a hospital by patients with severe or moderately severe haemophilia reduced from, on average, 20 days in 1972 to 3 days in 1992, due to a gradual decline in the percentage of patients requiring admission and a dimınished duration of stay. Haemophilia patients remained somewhat more dependent on hospital care in comparison with the average hospital usage of the Dutch male population in 1992 (3 days versus 1 day per year). However, their duration of stay per admission had become equal to that of Dutch males (10 days). In addition, the use of hospital facilities in patients with severe haemophilia had become the same as in those who were moderately severely affected.

Absenteeısm due to haemophilia, in school-going patients with severe or moderately severe haemophilia, dimınıshed from 32 days per year in 1972 to 5 days in 1992. As national statistics on school-absence are not avarlable, a comparison with Dutch males is not possible.

Table 1. Overview of self reported data obtained from four questionnaire surveys, presented for patients with severe and moderately severe haemophilia, the figures in parentheses only refer to patients with severe haemophilıa

\begin{tabular}{lcccc}
\hline & 1972 & 1978 & 1985 & 1992 \\
\hline$n$ & $242(159)$ & $351(245)$ & $559(384)$ & $560(387)$ \\
Mean age & $21(22)$ & $23(23)$ & $27(27)$ & $30(30)$ \\
Treatment modality & & & & \\
$\quad$ Prophylaxis (\%) & $21(30)$ & $33(40)$ & $36(48)$ & $45(59)$ \\
$\quad$ Home treatment (\%) & $4(5)$ & $25(30)$ & $53(67)$ & $62(77)$ \\
No of bleeds per year & $19(25)$ & $19(23)$ & $13(17)$ & $13(16)$ \\
Hospital admission per year & & & & \\
$\quad$ On average (days/patient) & $20(22)$ & $10(15)$ & $4(4)$ & $3(3)$ \\
$\quad$ Admitted (\%) & $47(51)$ & $37(40)$ & $23(25)$ & $22(22)$ \\
$\quad$ Duration of stay (days/patient) & $40(43)$ & $26(37)$ & $16(18)$ & $10(10)$ \\
Absenteeism (days/year) & & & & \\
$\quad$ From school* & $32(40)$ & $15(17)$ & $9(-10)$ & $5(6)$ \\
$\quad$ From work $\dagger$ & $26(31)$ & $35(39)$ & $20(18)$ & $22(21)$ \\
\hline
\end{tabular}

"Due to haemophilia in patients following full daytime education

$†$ Total absence in employed patıents aged $15-64$ years 
Table 2. Patients with severe haemophilia who reported serious imparment in one or more main joints, i e ankles, knees and elbows, with, in parentheses, the mean number of points severely damaged, stratıfied by age

\begin{tabular}{lcccc}
\hline Age & $\begin{array}{l}1972(n=159) \\
(\%(\text { mean }))\end{array}$ & $\begin{array}{l}1978(n=245) \\
(\%(\text { mean }))\end{array}$ & $\begin{array}{l}1985(n=384) \\
(\%(\text { mean }))\end{array}$ & $\begin{array}{l}1992(n=387) \\
(\% \text { (mean }))\end{array}$ \\
\hline 0-4 years & $8(01)$ & $0(00)$ & $0(00)$ & $0(00)$ \\
5-14 years & $9(01)$ & $11(02)$ & $6(01)$ & $0(00)$ \\
15-24 years & $25(04)$ & $17(03)$ & $10(01)$ & $18(02)$ \\
25-34 years & $50(08)$ & $32(05)$ & $32(06)$ & $32(06)$ \\
$35-44$ years & $53(09)$ & $32(06)$ & $47(09)$ & $52(12)$ \\
$45+$ years & $82(16)$ & $65(15)$ & $59(14)$ & $54(14)$ \\
All & $31(05)$ & $23(04)$ & $26(05)$ & $31(07)$ \\
\hline
\end{tabular}

Sick leave from work in haemophilıacs aged 15-64 years showed a less marked decline, with a reduction from 26 days in 1972 to 22 days per year in 1992 . From the selfreported data in 1992 it was calculated that 15 of the 22 days of absence $(68 \%)$ were attributable to haemophilia. Absenteeısm from work in 1992 was still 9 days higher in employed patients as compared to Dutch males who reported on average 13 days of absence per year.

\section{Joint impairment}

Table 2 shows percentages of severe haemophilia patients who reported serious joint impairment (score 3) in at least one of their ankles, knees or elbows, and the mean number of joints affected (range 1-6), stratified by age. No severe joint impairment was reported in patients aged 0-4 and 5-14 years in 1992. In the age category of 15-24 years there was no obvious improvement over the years in the percentage affected with severe joint impairment. In respondents aged 25-34 years this percentage initially dropped, from $50 \%$ to $32 \%$, but showed no further change. The overall joint status in the age category 35-44 years had not changed over 20 years, although the mean number of severely-impaired jounts had somewhat increased. Older patients $(45+)$ had gradually reported less severe impairment. Altogether, the proportion of severe haemophilia patients having at least one severely impaired joint had not changed over 20 years $31 \%$ in 1972 and 1992). Meanwhile, overall scores on the average number of affected joints had increased from 0.5 to 0.7 . Finally, $19 \%$ of all patients with severe haemophilia reported no joint impairment in 1992. This percentage was directly related to age no joint impairment at all in 1992 was reported by $86 \%$ of the patients aged $0-4,61 \%$ of those aged $5-14,15 \%$ of the young adults ( $15-24$ years), and $<2 \%$ of those aged 25 years and over.

\section{Employment and social participation}

The figures for participation in the national labour force of patients with severe or moderately severe haemophilia aged 15-64 years are shown in Table 3 . Those listed as 'active' participators had a pard job, and the category 'inactive' included those who were unemployed, disabled, early retired, or who participated in voluntary work. The percentage of patients with severe or moderately severe haemophilia listed as 'inactive' had increased over the 20 years. However, as national statistics for the same time showed an even larger increase in the number of inactive individuals, the excess of inactivity among patients compared to Dutch males decreased from $130 \%$ in 1972 to $30 \%$ in 1992 .

\section{HIV infections}

To assess HIV-related changes in outcome on hospitalizatıon, absenteeism and employment, we estımated firstly the prevalence of HIV infections based on answers to the

Table 3. Participation in the national labour force of patients with severe and moderately severe haemophilia aged 15-64 years who did not follow full daytime education, as compared to Dutch males, corrected for age

\begin{tabular}{|c|c|c|c|c|}
\hline & $\begin{array}{l}1972 \\
(n=113)\end{array}$ & $\begin{array}{l}1978 \\
(n=168)\end{array}$ & $\begin{array}{l}1985 \\
(n=330)\end{array}$ & $\begin{array}{l}1992 \\
(n=352)\end{array}$ \\
\hline $\begin{array}{l}\text { No of active patients }(\%) \\
\text { (\% active Dutch males) }\end{array}$ & $\begin{array}{r}89(79) \\
(91)\end{array}$ & $\begin{array}{r}116(69) \\
(85)\end{array}$ & $\begin{array}{r}215(65) \\
(77)\end{array}$ & $\begin{array}{r}227(64) \\
(73)\end{array}$ \\
\hline $\begin{array}{l}\text { No of inactive patients }(\%) \\
\text { (\% inactive Dutch males) }\end{array}$ & $\begin{array}{r}24(21) \\
(9)\end{array}$ & $\begin{array}{r}52(31) \\
(15)\end{array}$ & $\begin{array}{r}115(35) \\
(23)\end{array}$ & $\begin{array}{r}125(36) \\
(27)\end{array}$ \\
\hline $\begin{array}{l}\text { Inactıvity ratio } \\
\text { (haemophiliacs/Dutch males) }\end{array}$ & 23 & 21 & 15 & 13 \\
\hline
\end{tabular}


Table 4. Prevalence of HIV antıbodies in 1992 according to severity and for all

\begin{tabular}{lllll}
\hline & $\begin{array}{l}\text { Severe } \\
(n=378)\end{array}$ & $\begin{array}{l}\text { Moderate } \\
(n=173)\end{array}$ & $\begin{array}{l}\text { Mild } \\
(n=420)\end{array}$ & $\begin{array}{l}\text { All } \\
(n=980)\end{array}$ \\
\hline At risk $(n)^{\circ}$ & 328 & 136 & 243 & 707 \\
At risk and tested $(n)$ & 278 & 112 & 138 & 528 \\
Seropositive for HIV $(n)$ & 43 & 10 & 2 & 55 \\
Seropositivity if at risk $(\%)$ & 16 & 9 & 1 & 11 \\
\hline
\end{tabular}

"Patients who probably have been exposed to HIV infection durıng 1979-85

questionnaire in 1992 (Table 4). The percentage of HIVseropositive patients was calculated for those 'at risk', i.e. those who were born before June 1985 and had received treatment with blood products in the period 1979-85. Altogether, of 707 patients who had been exposed to untested blood products $528(75 \%)$ were tested for HIV. $11 \%(n=55)$ of these 528 patients were reported to be seropositive for HIV antibodies. The highest prevalence of $16 \%(43 / 278)$ was found among patients with severe haemophilia.

No excess of hospital admissions was observed in seropositive patients. $17 \%$ of the seropositive patients had to be admitted in 1992 and $22 \%$ of the seronegative patients with severe or moderately severe haemophilia. However, once admitted, the average duration of stay in hospital was more than twice as high in seropositive patients as in seronegative patients with severe or moderately severe haemophilıa (32 versus 14 days). Seropositive patients with severe or moderately severe haemophilıa who were undergoing full daytıme education, reported on average 10 days of absence from school. This was twice as high as in seronegative patients with severe or moderately severe haemophilıa (5 days). Sick leave from work in employed seropositive patients was not higher: 18 days versus 23 days per year in the seronegative patients with severe or moderately severe haemophilia. The inactivity ratio for seropositive patients was calculated at 1.4 (38\% versus $27 \%$ in Dutch males), whereas in seronegative patients this ratio was 1.2 .

\section{Discussion}

As modern haemophilia treatment alms to prevent arthropathy, by keeping the clotting factor activity above $1 \%$ of its normal value $[1,6]$ it can be expected that successful prevention is reflected in a decrease of the frequency of bleeds and a dimınıshed degree of joint imparment in severe haemophilia. Therefore, if comprehensive care methods were effective, the situation in severe haemophihacs would equal that of patients with moderately severe haemophilia. Subsequently, the social participation, absenteeism and hospitalization of haemophilia patıents would gradually become similar to that of the general male population.
The true prevalence of haemophilia in the Netherlands in 1992 was estımated at a value between the overall prevalence of 16.3 and the estimated maximum of 20.2 per 100,000 males (see Fig. 1). With a total of 7.48 million Dutch male inhabitants in 1992, the total number of haemophilıa patıents was approximately 1365 (range 1219-1511). Consequently, we reached about $93 \%$ of the Dutch haemophilia population in 1992, and approximately $72 \%$ of all patients participated in the questionnarre survey. In 1985 these two percentages were estımated at $95 \%$ and $75 \%$ [2]. By reaching a large majority of the haemophilic population, the reported data can be generalized for each severity category.

Since 1972 the use of prophylaxis in (moderately) severely affected patients more than doubled and the application of home treatment ended up 15 times higher. This shift in treatment modalities contributed to a decrease in the annual number of bleeds, especially in patients with severe haemophilia. Nonetheless, in the perspective of preventing all joint damage by preventing bleeds, the number of bleeds in patients with severe or moderately severe haemophilia was still disconcertıngly hıgh. As home treatment allows for prompt treatment, it is probable that home therapy contributed to the 'quality' of bleeds by reducing the severity of accompanying symptoms.

Modern haemophilia treatment succeeded in reducing the dependence on inpatient hospital care, as hospitalization in 1992 almost equalled that of the male population. Nonetheless, in 1992 the absence from school in patients with severe or moderately severe haemophilia was on average still 2-3 days higher than in patients with mild haemophilia, and sick leave from work remained higher in employed patients than in Dutch males. The participation of haemophilia patients in the national labour force in 1992 nearly equalled that of the Dutch male population, although the absolute number of unemployed and disabled haemophiliacs had increased over the years.

The consequences of HIV infections were reflected most obviously in the duration of hospital admission and absence from school in 1992. Although we must be careful in interpretıng the analyses with regard to the selfreported HIV test status in 1992, we tend to conclude that seropositivity did not result in any clear changes in the 
outcome measures used for assessing the effects of modern treatment. However, the $11 \%$ seropositivity for haemophilia patients in the Netherlands may have an impact that goes beyond the outcome reported in this article. The same might hold true for hepatitis infections, but because no self-reported test results on hepatitıs were avallable we cannot report on the consequences of hepatitis in this article. In a recent study we showed the impact of virus infections on mortality, with AIDS and liver disease becoming the main causes of death [13].

Contrary to expectation, the overall percentage of patients reporting severe joint impairment had not changed over 20 years. Despite the fact that factor preparations were readily available at an early age in patients born in the 1960 s, no obvious improvement in the joint status was observed for patients aged under 35 years in 1992. It can be questioned whether the self-rated degree of joint impairment used in the four questionnaire surveys is an accurate measure for assessing the effects of modern treatment methods. The Orthopedic Advisory Committee of the World Federation of Hemophilia recommended using the orthopaedic and radiological score system proposed by Pettersson [14]. However, as there is no clear relatıonshıp between radıologıcal scores and clinıcal observations [15-17] there might also be a discrepancy between such clinical measures and self-reported or subjective scores. According to Johnson \& Babbit [18], factors such as motivation, drive and personality traits might influence the perception of disability. In our selfassessment method it is likely that amongst temporary physical effects (e.g. recent acute bleeds) the reported degree of joint impairment was subject to person-related factors. Otherwise we would have to conclude that treatment modalities are still failing to prevent arthropathy. A more adequate prophylactıc treatment regimen, starting at an earlier age or with higher doses, will then be needed to produce better functional state. From our crosssectional data for 1992 it seems unlikely that the treatment method is inadequate in the Netherlands with respect to the onset of prophylaxis. Already $48 \%$ of patients with severe haemophilıa aged $0-4$ years receive prophylaxıs, $83 \%$ of those aged $5-9$, and $89 \%$ of patients aged $10-14$. After the age of 15 years the use of prophylaxis declined, from $72 \%$ in patients aged $15-24$ years to $69 \%$ in those aged 20-24 years. Since we did not enquire about the number of bleeds preceding the onset of prophylaxis, we cannot be sure whether young patients received prophylactic treatment in tıme, 1.e. when a process of arthropathy had not yet been initiated.

The question arises whether further improvements in the overall condition of haemophilia patients can be made. Our findings over a period of two decades suggest that the annual number of bleeds, absence from work and the degree of joint impairment can be dimınished, and

Haemophilia (1995), 1, 165-171 that social participation can be improved in (severe) haemophiliacs. With respect to joint status, a reduction is desirable in the degree of joint impairment reported by patients who were born at a tıme when substitution therapy already existed. In conclusion, the outcome measures over 20 years show that modern haemophilia treatment has led to improvements in the medical and social condition of patients. However, figures on the frequency of bleeds, absenteeism, joint impairment, and social participation can be improved further. Unless more attention is given to the prevention of (initial) joint damage, especially in adolescents and young adults, social inactivity in terms of disability and unemployment will remain higher in haemophiliacs than in the general male population. We stress the importance of closely monitoring young adults in whom initial joint damage may occur or progress.

\section{Acknowledgements}

We thank all patients who participated in the four questionnaure surveys. We also thank the following physicians of Dutch haemophilia treatment centres who contributed to the extensive patient registry L. J. Bosch (Diaconessenhuis Eindhoven), W. B. J. Gerrits (Leyenburg Hospital 's-Gravenhage), A. de Goede-Bolder (Sophia Hospital Rotterdam), K. Hamulyak (University Hospital Maastricht), H. Heijboer and M. Peters (Unıversity Hospital Amsterdam), A. Hensen (Kennemer Gasthuis Haarlem), A. C. J. M. Holdrinet (St Ignatius Hospital Breda), P. C. Huiggens (University Hospital Vrıje Universiteit Amsterdam), E. P. Mauser-Bunschoten and H. M. van der Berg (Van Creveld Clinıc Bilthoven), J. van der Meer and J. K. M. van Loon (University Hospital Gronıngen), H. K. Nieuwenhuis (Unıversity Hospital Utrecht), I. Novakova and C. G. van Oostrom (University Hospital St Radboud Nijmegen), J. A. van der Snoek (De Wever Hospital Heerlen) and J. Stıbbe (Unıversity Hospital Dijkzıcht Rotterdam).

The studies in 1985 and 1992 were supported by grants from Het Praeventiefonds (No. 28-1099 and 28-2139), the Netherlands.

\section{References}

1 Nilsson IM, Berntorp E, Lofquist T, Pettersson H Twentyfive years experience of prophylactic treatment in severe haemophilia A and B J Intern Med, 1992, 232: 25-32

2 Smit C, Rosendaal FR, Varekamp I, Brocker-Vriends A, Van Dijck H, Suurmeijer TPBM, Briet E Physical condition, longevity, and social performance of Dutch haemophiliacs, 1972-85. Brtt Med J, 1989, 298: 235-238.

3 Rosendaal FR, Smit C, Briet E Hemophilia treatment in historical perspective a review of medical and social developments Ann Hemat, 1991, 62: 5-15 
4 Rosendaal FR, Smıt C, Varekamp I, Brocker-Vriends AH, Van Dijck H, Suurmeıjer TP, et al. Modern haemophilıa treatment medical improvements and quality of life J Intern Med, 1990, 228: 633-640.

5 Rizza CR, Spooner RJD. Treatment of haemophilia and related disorders in Britain and Northern Ireland during 1976-80: report on behalf of the directors of haemophila centres in the United Kingdom. Brit Med J, 1983, 286: 92933.

6 Nilsson IM, Berntorp E, Lofquist T, Pettersson $H$. Prophylactic treatment of severe hemophilia A and B can prevent joint disability. Semin Hemat, 1994, 31 (Suppl. 2) 5-9.

7 Petrin P, Blomback M, Lindvall N. Prophylaxis with factor concentrates in preventing hemophilic arthropathy. Am J Paediatr Hemat Oncol, 1991, 13: 280-287.

8 Jones P Haemophilia home therapy. Haemostasts, 1992; 22 : 247-50.

9 Rizza CR, Spooner RJD. Home treatment of haemophilia and Christmas disease. five years experience. Brit J Haemat, 1977; 37: 53-66

10 Bohn RL, Avorn J. Cost-effectiveness, can it be measured Semin Hemat, 1993; 30 (Suppl 2) 20-23.

11 Hoskinson J, Duthie RB. Management of musculoskeletal problems in the hemophilias. Orthop Clm North Amer, 1978, 9: $455-480$.

12 Ahlberg A. Haemophilia in Sweden. VII. Incidence, treatment and prophylaxis of arthropathy and other musculoskeletal manifestations of haemophilıa A and B. Acta Orthop Scand, 1965, Suppl. 77: 7-80.

13 Triemstra AHM, Rosendaal FR, Smit C, Van der Ploeg HM, Briet E. Changes in mortality among hacmophilia patients. (Submitted).
14 Pettersson H, Glbert M. Diagnostic Imaging in Hemophilia; Musculoskeletal and Other Hemorrhagic Complications. Berlın: Sprınger, 1985 56-65.

15 Pettersson H. Can joint damage be quantified? Semın Hematol, 1994. 31 (Suppl. 2) 1-4.

16 Gilbert MS. Prophylaxıs' musculoskeletal evaluation. Semin Hemat, 1993, 30 (Suppl. 2). 3-6.

17 Gamble JG, Bellah J, Rinsky LA, Glader B. Arthropathy of the ankle in hemophilia. $J$ Bone Joint Surg, 1991; 73A: 10081015

18 Johnson RP, Babbitt DP. Five stages of joint disintegration compared with range of motion in hemophilia. Clin Orthop, 1985, 201: $36-42$.

\section{Authors}

A. H. Mattanja Triemstra, M.Sc., Research Fellow, Department of Medical Psychology, Vrije Universitert Amsterdam, the Netherlands.

Cees Smıt, NVHP Coordınator, Netherlands Hemophilıa Society (NVHP), Badhoevedorp, the Netherlands.

Henk M. van der Ploeg, Ph.D., Professor of Medical Psychology, Department of Medical Psychology, Vrije Universiteit Amsterdam, the Netherlands.

Ernest Brıet, M.D., Professor of Internal Medicıne, Hemostasıs and Thrombosis Research Centre, University Hospital Leiden, the Netherlands.

Frits R. Rosendaal, M.D., Epidemiologist, Department of Clinical Epidemiology, and Hemostasis and Thrombosis Research Centre, University Hospital Leiden, Buldıng 1, C0P45, PO Box 9600, 2300 RC Leiden, the Netherlands.*

*Address for correspondence 